ISSN 0103-8478

\title{
Morfogênese de plantas de alho in vitro: papel dos reguladores de crescimento na indução e desenvolvimento de bulbos
}

\author{
In vitro morphogenesis of garlic plants: The role of \\ growth regulators in bulb induction and development
}

\author{
Renato Luis Vieira ${ }^{{ }^{*}}$ Aparecido Lima da Silva ${ }^{I I}$ \\ Gilmar Roberto Zaffari ${ }^{\mathrm{I}}$ Anderson Luiz Feltrim ${ }^{\mathrm{I}}$
}

\section{RESUMO}

Protocolos eficientes de crescimento de ápices caulinares de alho (Allium sativum L.) e posterior bulbificação in vitro são importantes para limpeza clonal e manutenção da fidelidade genética. O trabalho teve como objetivo avaliar os efeitos de tipos e concentrações de reguladores de crescimento sobre a morfogênese de plantas de alho in vitro. Ápices caulinares com até dois primórdios foram excisados de bulbilhos de alho da cv. 'Jonas' e submetidos ao cultivo in vitro em meio de cultura suplementado de ácido indolacético $(0 ; 1,07 ; 2,69$ e 5,37 $\mu \mathrm{M})$, ácido indolbutírico $(0 ; 0,49 ; 0,98$ e 2,46 $\mu \mathrm{M})$, ácido naftalenoacético $(0$.

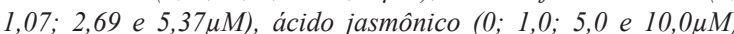
e ácido abscísico $(0 ; 0,38 ; 1,89 ;$ e 3,78 $\mu \mathrm{M})$. A concentração de $1,07 \mu \mathrm{M}$ de ácido naftalenoacético aplicado ao meio de cultura promoveu incrementos na maioria das variáveis analisadas. $O$ ácido jasmônico induziu a formação de bulbos de alho in vitro, embora tenha apresentado performance inferior ao verificado com o uso de ANA. Por outro lado, a adição de ácido abscísico no meio de cultura inibiu o crescimento de plantas, porém, não impediu a formação de bulbos, sobretudo em concentrações reduzidas. De um modo geral, as variáveis número de bulbos e porcentagem de bulbificação diminuiram com o uso de concentrações elevadas dos reguladores de crescimento testados. Entre os reguladores de crescimento de plantas, o ANA apresenta maior efeito na morfogênese in vitro de plantas de alho, entretanto, o ácido jasmônico e o ABA também apresentam potencial para induzir a formação de bulbos de alho in vitro como o ANA.

Palavras-chave: micropropagação, ápices caulinares, bulbificação, Allium sativum.

\section{ABSTRACT}

Efficient protocols for garlic (Allium sativum L.) shoot tips growth and later in vitro bulbing are significant for pathogen removal and maintenance of genetic fidelity. The objective of this study was to assess the effects of different types and concentrations of growth regulators on in vitro morphogenesis of garlic plants. Shoot meristems with up to two primordial were excised from garlic bulbils (cv. 'Jonas') and cultivated in vitro in culture media supplemented with indoleacetic acid $(0 ; 1,07 ; 2,69$ e 5,37 $\mu \mathrm{M})$,

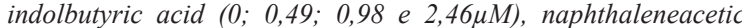
acid (0; 1,07; 2,69 e 5,37 $\mu \mathrm{M})$, and abscisic acid (0; 0,38; 1,89; e $3,78 \mu \mathrm{M})$. The concentration of 1,07 $\mu \mathrm{M}$ indoleacetic acid applied to the culture medium promoted increases in most variables analyzed. Jasmonic acid induced formation of garlic bulbs in vitro, although it showed lower performance than that verified with the use of NAA. On the other hand, addition of abscisic acid in culture media inhibited plant growth. However, it did not impede the formation of bulbs, especially when in reduced concentrations. Generally speaking, variables such as number of bulbs and rate of bulbing decreased with the use of high concentrations of the assessed growth regulators. Among plant growth regulators, NAA showed a stronger effect on in vitro morphogenesis of garlic plants. Nonetheless, jasmonic acid and ABA also showed potential to induce formation of garlic bulbs in vitro such as NAA.

Key words: micropropagation, shoot tips, bulbing, Allium sativum.

\section{INTRODUÇÃO}

Diversos ensaios foram realizados in vitro com o gênero Allium focando vários objetivos, tais como: conservação de germoplasma (ELLIS et al., 2005), estudos sobre embriogênese somática (FEREOL et al., 2002) e transformação genética (KENEL et al., 2010). Entretanto, a limpeza clonal através da cultura de ápices caulinares é, sem dúvida, a técnica de cultura de tecidos vegetais mais regularmente aplicada às espécies desse gênero.

\footnotetext{
'Empresa de Pesquisa Agropecuária e Extensão Rural de Santa Catarina (EPAGRI), 89500-000, Caçador, SC, Brasil. E-mail: revieira@epagri.sc.gov.br.*Autor para correspondência.

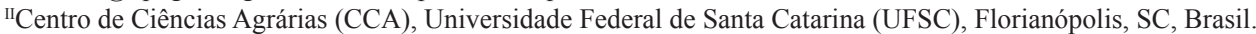
Recebido 16.08.12 Aprovado 11.08.13 Devolvido pelo autor 09.12.13 CR-2012-0688.R1
} 
Entre uma série de fatores que influenciam a indução e crescimento de órgãos de armazenamento in vitro pode-se destacar: a composição genética da planta, suplementos adicionados ao meio de cultura e condições ambientais. A composição genética da planta depende da família, e esta, principalmente determina o tipo de explante que é mais comumente usado (ASCOUGH et al., de 2008). Por exemplo, explantes foliares de Amaryllidaceae e Iridaceae não são responsivos em meio de cultura, assim escamas e rebentos são utilizados, respectivamente (MEDINA et al., 2009).

Os componentes do meio de cultura, tais como: formulação salina, reguladores de crescimento vegetal, hidratos de carbono, meio de geleificação e adição de outros novos agentes podem ser ajustados para a indução de órgãos de armazenamento em uma espécie em particular (MEDINA et al., 2009). A formulação salina MS (MURASHIGE \& SKOOG, 1962), que é universalmente empregada no cultivo in vitro de grande quantidade de espécies, é o meio básico normalmente utilizado para as espécies do gênero Allium.

$\mathrm{O}$ uso dos fitorreguladores ANA (ácido naftalenoacético) e BAP (6-benzilaminopurina) tem demonstrado eficiência na micropropagação de alho. HAVRANÉK (1972) cultivou ápices caulinares com 0,4 a $0,6 \mathrm{~mm}$ de tamanho e obteve desenvolvimento inicial de plantas, bulbificação e enraizamento, em meio MS com adição de vitaminas, sacarose $\left(20 \mathrm{~g} \mathrm{~L}^{-1}\right) \mathrm{e}$ ANA na concentração de $\left(1 \mathrm{mg} \mathrm{L}^{-1}\right)$. Os efeitos de ANA e BAP foram avaliados por MATSUBARA \& CHEN (1989) em meio de cultura para desenvolvimento de explantes, enraizamento e bulbificação em plantas de alho, ambos na concentração de $0,1 \mathrm{mg} \mathrm{L}^{-1}$. Esses autores observaram que nessas condições as plantas desenvolviam-se com maior vigor e com maior capacidade de aclimatização em condições de campo. Em concentração mais elevada de $\operatorname{BAP}\left(0,3 \mathrm{mg} \mathrm{L}^{-1}\right)$ no meio de cultura, CONCI (1997) obteve plantas de alho livres de vírus com formação média de quatro bulbilhos a partir de um único meristema isolado.

A efetividade da citocinina 6-benzilaminopurina (BAP) e da auxina ácido naftaleno acético (ANA) na regeneração de plantas de alho já foi comprovada, entretanto, a taxa média de multiplicação observada de 1,5 bulbilhos por explante foi considerada baixa. Outros reguladores do crescimento foram utilizados com êxito em meios de cultura para micropropagação do alho. ROSSI et al. (1995) obtiveram, para a cultivar 'Piacentino Bianco', uma proliferação no número de bulbos de 1:4,5 utilizando o meio MS modificado, acrescido de Tidiazuron (TDZ).

Diversos trabalhos atribuem aos jasmonatos efeitos indutivos à formação de bulbos em algumas espécies de plantas cultivadas in vitro. NOJIRI et al. (1992) demonstraram que as concentrações endógenas de ácido jasmônico (AJ) foram diferentes na bulbificação e não bulbificação de partes de plantas de cebola. Em combinação com 2iP (isopenteniladenina), a aplicação exógena de AJ estimulou a indução de brotações em fragmentos basais de bulbilhos de alho, que ainda resultou em uma alta porcentagem de formação de bulbos (ZEL et al., 1997). Os jasmonatos podem ainda estar envolvidos no processo de formação de órgãos de armazenamento em geral, estimulando a tuberização em batata, inhame e alcachofra (KODA, 1992). Contudo, poucos relatos são dedicados aos seus efeitos na micropropagação do alho, sobretudo, no cultivo de ápices caulinares com o objetivo de recuperar plantas livres de vírus.

Estudos sobre efeitos da aplicação exógena de ABA para micropropagação de várias espécies apontam evidências do seu envolvimento no processo de formação de órgão de reservas (SATO et al., 2001), podendo exercer efeitos estimulatórios em vários níveis: morfológicos, fisiológicos, celulares e moleculares (PARTHIER et al., 1992).

ALIZADEH (1998) observou forte efeito inibitório do $\mathrm{ABA}$ na micropropagação de Dioscorea composita, porém, com a presença de microtubérculos na base das plantas, fato que não foi observado no trabalho de SATO et al. (2001) na regeneração in vitro de mandioca. PILET \& BARLOW (1987) apontam o ABA também como um inibidor do crescimento da raiz em sistemas de cultivo in vitro, contrariando resultados de estudos anteriores que mostram aumento no crescimento da raiz em presença do ABA, especialmente, quando usado em baixas concentrações (YAMAGUCHI \& STREET, 1977). Apesar das evidências demonstradas em outras espécies formadoras de órgãos de armazenamento, ainda não há um consenso científico sobre o envolvimento do ABA na indução e desenvolvimento de bulbos de alho.

O presente trabalho teve por objetivo avaliar os efeitos de reguladores de crescimento sobre a morfogênese de plantas de alho in vitro.

\section{MATERIAL E MÉTODOS}

Os experimentos foram conduzidos no Laboratório de Cultura de Tecidos de Plantas da Epagri/Estação Experimental de Caçador (Caçador/ SC) no período de 30/05/2011 a 30/11/2011. Bulbilhos de alho da cultivar nobre 'Jonas', provenientes do Banco Ativo de Germoplasma de alho da Epagri, 
foram utilizados para a extração de ápices caulinares com até dois primórdios foliares. Os explantes meristemáticos foram excisados de bulbilhos previamente desinfestados em álcool 70\% (1 minuto) e hipoclorito de sódio 1,5\% (20 minutos), seguido de tríplice lavagem em água destilada esterilizada. Os ápices caulinares foram submetidos a duas fases de cultivo in vitro: na primeira, para o desenvolvimento inicial da planta (Fase de iniciação) e, na segunda fase, para o crescimento da planta, enraizamento e indução de bulbos (Fase de bulbificação).

$\mathrm{Na}$ fase de iniciação, os ápices caulinares foram introduzidos em tubos de ensaio $(15 \mathrm{mmx} 100 \mathrm{~mm})$ com $3 \mathrm{ml}$ de meio MS (MURASHIGE \& SKOOG, 1962), com redução de dois terços da concentração salina (MS/3), suplementado de vitaminas (Tiamina, Piridoxina, Glicina e Ácido Nicotínico), Mio-Inositol (100mg $\left.\mathrm{L}^{-1}\right)$, sacarose (3\%), 6-benzilaminopurina $\left(0,1 \mathrm{mg} \mathrm{L}^{-1}\right)$ e geleificado com ágar $(0,6 \%)$ (VIEIRA, 2012).

$\mathrm{Na}$ fase de bulbificação, as plantas em fase inicial de desenvolvimento, com 30 dias, foram transferidas individualmente para tubos de ensaio $(20 \mathrm{~mm} \times 150 \mathrm{~mm}$ ) contendo $8 \mathrm{ml}$ de meio MS, suplementado de vitaminas, Mio-Inositol (100mg $\left.\mathrm{L}^{-1}\right)$, sacarose $(3 \%)$ e dos seguintes reguladores de crescimento de plantas: AIA (ácido indolacético) (0; $1,07 ; 2,69$ e $5,37 \mu \mathrm{M})$, AIB (ácido indolbutírico) (0; 0,49; 0,98 e 2,46 $\mu \mathrm{M}$ ), ANA (ácido naftalenoacético) $(0 ; 1,07 ; 2,69$ e $5,37 \mu \mathrm{M})$, AJ (ácido jasmônico) ( 0 ; $1,0 ; 5,0$ e $10,0 \mu \mathrm{M})$ e ABA (ácido abscísico) $(0 ; 0,38$; $1,89$; e $3,78 \mu \mathrm{M})$. Para cada regulador de crescimento testado, os tratamentos foram constituídos pelos níveis de concentração. Em ambas as fases de cultivo, o $\mathrm{pH}$ dos meios de cultura foi ajustado para 5,8, antes da autoclavagem a $1,5 \mathrm{~atm}$ por 15 minutos.

As culturas foram mantidas em sala de crescimento com temperatura de $25 \pm 2^{\circ} \mathrm{C}$, fotoperíodo de $16 \mathrm{~h}$ e intensidade luminosa ajustada para 60 a $70 \mu \mathrm{mol}$ de fótons $\mathrm{m}^{-2} \mathrm{~s}^{-1}$ de lâmpadas fluorescentes brancas, durante as duas fases de crescimento.

O experimento foi conduzido em delineamento experimental inteiramente casualisado, com 20 repetições por tratamento. A repetição foi constituída de um tubo de ensaio contendo cada um uma planta em fase inicial de desenvolvimento.

Outros reguladores de crescimento foram analisados individualmente, como experimentos distintos. Os dados de diâmetro de bulbo, massa fresca de bulbo, altura de plantas, número de raízes por planta e número de folhas por planta foram sumetidos às análises de variância (teste F) e as variáveis número de bulbos por planta e porcentagem de bulbificação foram submetidas à análise não paramétrica (teste Kruskal-Wallis), por não terem apresentado distribuição normal para nenhum dos dois fatores testados. Foi utilizado o programa SAS (versão 9.0) e as médias comparadas pelo teste de Tukey a $5 \%$ de probabilidade de erro.

\section{RESULTADOS E DISCUSSÃO}

Na tabela 1, encontram-se os valores médios das variáveis de crescimento de bulbo e parte aérea de plantas de alho micropropagadas sob diferentes tipos e concentrações de reguladores de crescimento de plantas (RCPs). Houve poucos ajustes significativos nas regressões polinomiais, por isso optou-se por realizar testes de comparações múltiplas de média.

Melhor resultado para número de bulbos por planta $(1,6)$ e porcentagem de bulbificação (100\%) foi observado quando se aplicou $1,07 \mu \mathrm{M}$ de ANA, seguido do Ácido Jasmônico (AJ) que, adicionado ao meio de cultura na concentração de até $5 \mu \mathrm{M}$ promoveu incrementos dessas duas variáveis. Essas duas variáveis diminuíram com o uso de concentrações crescentes dos RCPs, chegando a inibi-las completamente com o uso de ABA na concentração de $3,78 \mu \mathrm{M}$.

Não há ainda um consenso científico sobre o envolvimento do ABA na indução e formação de órgãos de armazenamento, incluindo bulbos em espécies do gênero Allium. KIM (1994) verificou que a adição de fluridone, um inibidor da síntese de ABA, em meio de regeneração de plantas de Lillium speciosum, causou inibição do crescimento da parte aérea, porém não impediu a formação de bulbos nessa espécie. Por outro lado, YAMASAKI et al. (1999) relatam que o ABA não está diretamente associado com a indução de bulbos em plantas de Allium wakagi micropropagadas.

Em espécies de outros gêneros, como em Hyacinthus orientalis, a regeneração e crescimento de bulbilhos diminuíram proporcionalmente com aumento da concentração de ABA (PIERIK e STEEGMANS, 1975), fato igualmente observado por CHEESMAN et al. (2010) em Eucomis Zambesiaca. No presente trabalho, o ABA foi o RCP que apresentou efeitos menos eficazes, tendo o maior número de bulbos $(0,7)$ e a máxima porcentagem de bulbificação (60\%), obtidos com o menor nível de concentração utilizada $(0,38 \mu \mathrm{M})$.

Houve efeito significativo das concentrações dos RCPs para as demais variáveis analisadas pelo teste $\mathrm{F}(p \leq 0,05)$. Novamente o ANA, na concentração de $1,07 \mu \mathrm{M}$, promoveu o 
Tabela 1 - Efeito da concentração dos reguladores de crescimento AIA, AIB, ANA, ABA e AJ em plantas de alho, cultivar Jonas, após 110 dias de cultivo in vitro. Caçador, SC, 2011.

\begin{tabular}{|c|c|c|c|c|c|c|c|}
\hline $\begin{array}{l}\text { Concentração } \\
\text { de RCPs }(\mu \mathrm{M})\end{array}$ & $\begin{array}{l}\text { Número de } \\
\text { bulbos por } \\
\text { planta }^{1}\end{array}$ & $\begin{array}{c}\text { bulbificação }^{1} \\
(\%)\end{array}$ & $\begin{array}{l}\text { Diâmetro de } \\
\text { bulbo }^{2}(\mathrm{~mm})\end{array}$ & $\begin{array}{c}\text { Massa fresca } \\
\text { de bulbo }(\mathrm{mg})\end{array}$ & $\begin{array}{c}\text { Altura de } \\
\text { plantas }^{2}(\mathrm{~cm})\end{array}$ & $\begin{array}{l}\text { Número de } \\
\text { raízes por } \\
\text { planta }^{2}\end{array}$ & $\begin{array}{l}\text { Número de } \\
\text { folhas por } \\
\text { plantas }^{2}\end{array}$ \\
\hline \multicolumn{8}{|c|}{-------------------------- Experimento 1 (AIA) -------------------------- } \\
\hline 0 & $0,40 \beta$ & $30,0 \beta$ & $3,88 \mathrm{c}$ & $155,2 \mathrm{c}$ & $4,70 \mathrm{~d}$ & $1,00 \mathrm{c}$ & $3,00 \mathrm{~b}$ \\
\hline 1,07 & $0,90 \alpha \beta$ & $70,0 \alpha \beta$ & $6,10 \mathrm{a}$ & $197,2 \mathrm{a}$ & $9,34 \mathrm{c}$ & $9,10 \mathrm{a}$ & $4,20 \mathrm{a}$ \\
\hline 2,69 & $1,20 \alpha$ & $100,0 \alpha$ & $5,54 \mathrm{~b}$ & $188,2 \mathrm{ab}$ & $11,25 \mathrm{~b}$ & $8,80 \mathrm{a}$ & $4,20 \mathrm{a}$ \\
\hline 5,37 & $0,50 \alpha \beta$ & $40,0 \alpha \beta$ & $5,26 \mathrm{~b}$ & $179,2 \mathrm{~b}$ & $12,64 \mathrm{a}$ & $5,40 \mathrm{~b}$ & $4,10 \mathrm{a}$ \\
\hline CV (\%) & 47,2 & 31,4 & 5,8 & 6,2 & 5,1 & 22,1 & 19,3 \\
\hline \multicolumn{8}{|c|}{------------------------ Experimento 2 (AIB) ----------------------- } \\
\hline 0 & 0,40 & 30,0 & 3,88 & $155,2 \mathrm{c}$ & $4,70 \mathrm{c}$ & $1,00 \mathrm{c}$ & $3,00 \mathrm{~b}$ \\
\hline 0,49 & 0,80 & 60,0 & 4,20 & $182,7 \mathrm{a}$ & $11,50 \mathrm{a}$ & $8,10 \mathrm{a}$ & $4,10 \mathrm{a}$ \\
\hline 0,98 & 0,40 & 40,0 & 3,92 & $161,2 \mathrm{bc}$ & $11,94 \mathrm{a}$ & $6,90 \mathrm{a}$ & $3,90 \mathrm{a}$ \\
\hline 2,46 & 0,20 & 10,0 & 4,10 & $177,5 \mathrm{ab}$ & $6,53 \mathrm{~b}$ & $3,60 \mathrm{~b}$ & $2,80 \mathrm{~b}$ \\
\hline $\mathrm{CV}(\%)$ & 48,1 & 33,0 & 7,8 & 4,9 & 9,7 & 27,7 & 17,7 \\
\hline \multicolumn{8}{|c|}{ 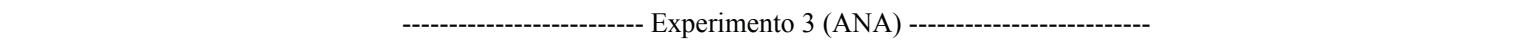 } \\
\hline 0 & $0,40 \beta$ & $30,0 \beta$ & $3,88 \mathrm{~b}$ & $155,25 \mathrm{c}$ & $4,70 \mathrm{c}$ & $1,00 \mathrm{~b}$ & $3,00 \mathrm{~b}$ \\
\hline 1,07 & $1,60 \alpha$ & $100,0 \alpha$ & $6,37 \mathrm{a}$ & $213,00 \mathrm{a}$ & $9,77 \mathrm{~b}$ & $7,30 \mathrm{a}$ & $3,90 \mathrm{a}$ \\
\hline 2,69 & $1,00 \alpha \beta$ & $70,0 \alpha \beta$ & $6,33 \mathrm{a}$ & $205,40 \mathrm{a}$ & $10,29 \mathrm{ab}$ & $7,10 \mathrm{a}$ & $4,33 \mathrm{a}$ \\
\hline 5,37 & $0,70 \alpha \beta$ & $60,0 \alpha \beta$ & $4,04 \mathrm{~b}$ & $169,29 \mathrm{~b}$ & $10,83 \mathrm{a}$ & $7,80 \mathrm{a}$ & $4,00 \mathrm{a}$ \\
\hline $\mathrm{CV}(\%)$ & 28,3 & 65,9 & 4,9 & 3,4 & 6,2 & 19,2 & 17,2 \\
\hline \multicolumn{8}{|c|}{ 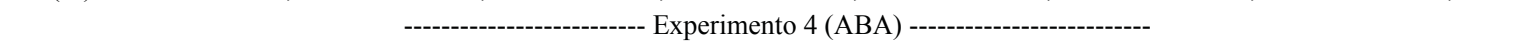 } \\
\hline 0 & $0,40 \alpha \beta$ & $30,0 \alpha \beta$ & $3,88 \mathrm{a}$ & 155,25 & $4,70 \mathrm{a}$ & $1,00 \mathrm{c}$ & $3,00 \mathrm{a}$ \\
\hline 0,38 & $0,70 \alpha$ & $60,0 \alpha$ & $3,47 \mathrm{~b}$ & 145,43 & $5,16 \mathrm{a}$ & $3,90 \mathrm{~b}$ & $3,40 \mathrm{a}$ \\
\hline 1,89 & $0,30 \alpha \beta$ & $30,0 \alpha \beta$ & $3,57 \mathrm{ab}$ & 143,33 & $4,11 \mathrm{~b}$ & $5,50 \mathrm{a}$ & $2,70 \mathrm{ab}$ \\
\hline 3,78 & $0,00 \beta$ & $0,00 \beta$ & nd & nd & $2,83 \mathrm{c}$ & $1,90 \mathrm{c}$ & $1,67 \mathrm{~b}$ \\
\hline $\mathrm{CV}(\%)$ & 85,0 & 72,7 & 6,4 & 4,8 & 10,4 & 36,9 & 23,2 \\
\hline \multicolumn{8}{|c|}{ 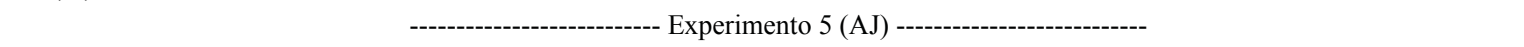 } \\
\hline 0 & $0,40 \beta$ & $30,0 \beta$ & $3,88 \mathrm{~b}$ & $155,25 \mathrm{~b}$ & $4,70 \mathrm{c}$ & $1,00 \mathrm{~b}$ & $3,00 \mathrm{ab}$ \\
\hline 1 & $0,60 \alpha \beta$ & $60,0 \alpha \beta$ & $3,27 \mathrm{c}$ & $140,00 \mathrm{c}$ & $7,53 \mathrm{a}$ & $2,30 \mathrm{~b}$ & $3,40 \mathrm{a}$ \\
\hline 5 & $1,40 \alpha$ & $100,0 \alpha$ & $5,38 \mathrm{a}$ & $215,60 \mathrm{a}$ & $7,39 \mathrm{a}$ & $5,60 \mathrm{a}$ & $3,20 \mathrm{a}$ \\
\hline 10 & $0,70 \alpha \beta$ & $50,0 \alpha \beta$ & $3,56 \mathrm{bc}$ & $104,00 \mathrm{~d}$ & $5,43 \mathrm{~b}$ & $6,20 \mathrm{a}$ & $2,20 \mathrm{~b}$ \\
\hline CV $(\%)$ & 44,1 & 73,5 & 4,8 & 4,0 & 7,0 & 49,5 & 23,7 \\
\hline
\end{tabular}

Teste $x^{2}$ significativo $\left.(p \leq 0,05)\right) ;{ }^{2)}$ Teste F significativo $(p \leq 0,05)$; nd: não determinado. Médias seguidas pela mesma letra na coluna não diferem pelo teste de Tukey, a 5\% de probabilidade de erro. Médias seguidas pela mesma letra grega na coluna não diferem pelo teste de Kruskal-Wallis duas a duas, a 5\% de probabilidade de erro. RCPs: reguladores de crescimento de plantas; AIA: ácido indolacético; AIB: ácidoindolbutírico; ANA: ácido naftalenoacético; ABA: ácido abscísico; AJ: ácido jasmônico.

melhor resultado, particularmente para as variáveis diâmetro e massa fresca do bulbo. Verificouse, ainda em relação ao ANA, que nas variáveis número de raízes por planta e número de folhas por planta, as concentrações utilizadas resultaram em diferenças significativas apenas em relação ao tratamento controle. Apesar da ausência de RCP no meio de cultura (tratamento controle), houve resposta no crescimento para a maioria das variáveis estudadas. De acordo com KERBAUY (1999), ápices caulinares possuem competência e determinação para crescimento, desde que sejam fornecidas as condições necessárias de nutrição e luminosidade. Segundo esse mesmo autor, auxinas e citocininas endógenas são sintetizadas pelos primórdios foliares dos ápices caulinares e radícula, respectivamente, e podem suprir a demanda para crescimento e enraizamento.

As auxinas AIA e AIB promoveram aumento do número de raízes por planta em concentrações mais baixas. Entretanto, ocorreram diminuições significativas sob o efeito de concentrações mais elevadas, particularmente com o suplemento de $2,46 \mu \mathrm{M}$ de AIB no meio de cultura, que ainda resultou num expressivo número de plantas com formação de calo na base, o que é indesejável na reprodução de clones. No presente estudo, 
considerou-se que os níveis das auxinas contidas no meio para indução de bulbo proporcionaram o desenvolvimento do sistema radicular e da parte aérea, necessário à propagação da espécie. Resultados semelhantes ao deste trabalho têm sido relatados com sucesso para outras espécies bulbosas, como Narcissus (SEABROOK, 1990), e para raízes de mandioca (SATO et al., 2001) submetidas ao meio de cultura suplementados de auxinas.

O meio com ausência de auxinas (tratamento controle) promoveu maior crescimento da parte aérea $(4,7 \mathrm{~cm})$ em relação às raízes. Em outras espécies regeneradas in vitro, como em amoreira, a ausência de auxina no meio de cultura não inibiu o número e alongamento das raízes (RADMANN et al., 2003). Essa condição, segundo GEORGE et al. (2008), pode também estimular o crescimento in vitro da parte aérea de plantas, fato não verificado no presente estudo. É comum ocorrer respostas diferenciadas à auxina entre e dentro de espécie. HUSSEY (1982) relatou a variação genética na sensibilidade de cultura de brotos de Narcissus para reguladores de crescimento das plantas, entretanto, diversas cultivares dessa mesma espécie, utilizadas nos experimentos de Chow et al. (1992), responderam de forma semelhante aos tratamentos instituídos.

O ABA adicionado no meio de cultura de bulbificação promoveu o menor crescimento da parte aérea, revelado pela altura de plantas e número de folhas, o que sugere um efeito inibitório desse hormônio no crescimento de plantas de alho in vitro. A amplitude de variação da altura de plantas foi de $2,83 \mathrm{~cm}$, com o maior valor de $5,16 \mathrm{~cm}$, alcançado com a aplicação de $0,38 \mu \mathrm{M}$ de $\mathrm{ABA}$, porém, não diferiu do tratamento controle $(4,7 \mathrm{~cm})$.

É reconhecido que os jasmonatos apresentam ações biológicas bastantes semelhantes atribuídas ao ácido abscísico, como efeito inibitório do crescimento vegetal (PARTHIER et al., 1992). No entanto, da mesma forma descrita para o ABA, os jasmonatos, dependendo da concentração empregada, podem também exercer efeitos estimulatórios em vários níveis: morfológicos, fisiológicos, celulares e moleculares (PARTHIER et al., 1992).

No presente estudo, o aumento das concentrações do Ácido Jasmônico até o nível de $5 \mu \mathrm{M}$ apresentou efeito positivo no crescimento da maioria das variáveis analisadas. Por outro lado, a concentração de $10 \mu \mathrm{M}$ inibiu o crescimento da parte aérea, caracterizado pelo baixo número de folhas e redução na altura das plantas. Há relatos em que o Ácido Jasmônico aumentou a indução e tamanho de bulbos em Allium sativum cv. 'Ptuj' (RAVNIKAR et al., 1993) e Narcissus triandrus (SANTOS \& SALEMA, 2000), porém, não estimulou formação de bulbo em Eucomis zambesiaca em nenhuma concentração utilizada (CHEESMAN et al., 2010).

Diferentemente do resultado obtido por ZEL et al. (1997), no qual a formação de raízes em plantas de alho regeneradas a partir de fragmentos do disco caulinar foi inibida na presença de AJ, no presente trabalho, o número de raízes por planta manteve incrementos até o nível de $10 \mu \mathrm{M}$ de AJ. Estas variações podem ser atribuídas ao fato de diferentes espécies e/ou secções de vários órgãos diferirem em sua habilidade de produzir substâncias de crescimento endógena ou diferirem na sua concentração no momento do isolamento (HEMPEL, 1979).

\section{CONCLUSÃO}

Entre os reguladores de crescimento de plantas, o ANA foi mais efetivo na indução de bulbos de alho in vitro. O Ácido Jasmônico e o ABA também apresentam potencial para induzir a formação de bulbos de alho in vitro. Concentrações elevadas dos reguladores de crescimento promovem efeito negativo na morfogênese in vitro de plantas de alho.

\section{AGRADECIMENTOS}

Os autores agradecem à Empresa Brasileira de Pesquisa Agropecuária (EMBRAPA), pelo apoio financeiro a esta pesquisa.

\section{REFERÊNCIAS}

ALIZADEH, S. In vitro shoot culture and microtuber induction in steroid yam Dioscorea composita Hemsl. Plant Cell, Tissue Organ Culture, Dordrecht, v.53, p.107-112, 1998. Disponível em: <http:// link.springer.com/article/10.1023\%2FA\%3A1006036324474>. Acesso em: 06 jun. 2012. doi: 10.1023/A:1006036324474.

ASCOUGH, G.D. et al. In vitro storage organ formation on ornamental geophytes. Horticultural Reviews, v.34, p.417444, 2008. Disponível em: <http://onlinelibrary.wiley.com / doi/10.1002/9780470380147.ch7/summary>. Acesso em: 28 jun. 2012. doi: $10.1002 / 9780470380147 . \operatorname{ch} 7$

CHEESMAN, L. et al. Eucomis zambesiaca baker: Factors affecting in vitro bulblet induction. South African Journal of Botany, v.76, n.3, p.543-549, 2010. Disponível em: <http://www. researchgate.net/publication/222997375>. Acesso em: 15 jun. 2012. doi: 10.1016/j.sajb.2010.04.004

CHOW, Y.N. et al. Stimulation by sucrose of Narcissus bulbil formation in vitro. The Journal of Horticulturae Science \& Biotechnology, v.67, p.289-293, 1992. Disponível em: <http:// www.jhortscib.org/Vol67/67_2/19.htm>. Acesso em: 05 jun. 2012.

CONCI, V.C. Vírus y Fitoplasmas de ajo. In: BURBA, J. L. (Ed.) 50 temas sobre produccion de ajo - Ingenieria 
de cultivo. Mendonza: EEA La consulta. 1997, v.3, p.267291 .

ELLIS, D.M. et al. Cryopreservation of 12 Allium sativum accessions: a comparison of plant vitrification solutions pvs2 and pvs3. In Vitro Cellular and Developmental Biology, v.7, p. 11-12, 2005. Disponível em: <http://www.ars.usda.gov/research/ publications/publications.htm?seq_no_115 $=179195>$. Acesso em: 03 jun. 2012.

FEREOL, L. Et al. Evidence of a somatic embryogenesis process for plant regeneration in garlic (Allium sativum L.). Plant Cell Reports, v.21, n.3, p.197-203, 2002. Disponível em: <http://link. springer.com/article/10.1007\%2Fs00299-002-0498-0>. Acesso em: 15 jul. 2012. doi: 10.1007/s00299-002-0498-0.

GEORGE, E. F. et al. Plant propagation by tissue culture: the background. 3.ed. Dordrecht: Springer, v.1, 2008.

HAVRANEK, P. Vírus-free clones obtained from meristem cultures. Ochrana Rostlin, v.8, p.291-298, 1972. Disponível em: <http:// ecoport.org/ep?SearchType $=$ reference $\&$ ReferenceID $=45074>$. Acesso em: 10 jul. 2012.

HEMPEL, M. Application of growth regulators for in vitro propagation of ornamental plants. Acta Horticulturae, v.91, p.247-260, 1979. Disponível em: <http://www.actahort.org/ books/91/91_29.htm>. Acesso em: 15 jun. 2012.

HUSSEY, G. In vitro propagation of Narcissus. Annals of Botany, v.49, p.707-719, 1982. Disponível em: <http://aob.oxfordjournals. org/content/49/5/707>. Acesso em: 10 jul. 2012.

KENEL, F. et al. Efficient Agrobacterium tumefaciensmediated transformation and regeneration of garlic (Allium sativum L.) immature leaf tissue. Plant Cell Reports, v.29, p. 223-230, 2010. Disponível em: <http://www.researchgate.net/ publication/41124446>. Acesso em: 03 jun. 2012. doi: 10.1007/ s00299-009-0814-z.

KERBAUY, G.B. Competência e determinação celular em cultura de células e tecidos de plantas. In: TORRES, A.C. et al. (Eds.). Cultura de tecidos e transformação genética de plantas. Brasília: Embrapa-SPI, 1999. v.2, p.519-531.

KODA, Y. The role of jasmonic acid and related compounds in the regulation of plant evelopment. International Review of Cytology. v.133, p.133-199, 1992. Disponível em: <http://www.sciencedirect. com/science/article/pii/S0074769608620409>. Acesso em: 15 jun. 2012. doi: org/10.1016/S0074-7696(08)62040-9.

MATSUBARA, S.; CHEN, D. In vitro production of garlic plants and field acclimatization. HortScience, v.24, n.4, p.677-679, 1989. Disponível em: <http:/geoscience.net/research/007/439/in-vitroproduction-garlic-plants-field- acclimatization.php $>$. Acesso em: 10 jul. 2012.

MEDINA, R. D.; et al. In vitro tuberization and plant regeneration from multimodal segment culture of Habenaria bractescens Lindl., an Argentinean wetland orchid. Plant Cell Tissue Organ Culture, v.97, p.91-101, 2009. Disponível em: <http://link. springer.com/article/10.1007/s11240-009-9505-2>. Acesso em: 05 jun. 2012. doi: 10.1007/s11240-009-9505-2.

MURASHIGE, T.; SKOOG, F. A revised medium for rapid growth and biossays with tobacco tissue cultures. Physiologia Plantarum, v.15, p.473-497, 1962. Disponível em: <http://onlinelibrary.wiley. com/doi/10.1111/j.1399-3054.1962.tb08052.x/abstract>. Acesso em: 15 jul. 2012. doi: 10.1111/j.1399-3054.1962.tb08052.x.

NOJIRI, H. et al. Qualitative and quantitative analysis of endogenous jasmonic acid in bulbing and non-bulbing onion plants. Plant Cell Physiology, v.33, p.1225-1231, 1992. Disponível em: <http://pcp.oxfordjournals.org/content/33/8/1225.abstract>. Acesso em: 05. Jul. 2012.

PARTHIER, B. et al. Jasmonates: metabolism, biological activities, and modes of action in senescense and strees responses. Progress in Plant Growth Regulation, v.13, p.276-285, 1992. Disponível em: <http://link.springer.com/ chapter/10.1007/978-94-011-2458-4_30>. Acesso em 05 jun. 2012. doi: 10.1007/978-94-011-2458-4_30.

PIERIK, R.L.M., STEEGMANS, H.H.M. Effect of auxins, cytokinins, gibberellins, abscisic acid and ethephon on regeneration and growth of bulblets on excised bulb scale segments of Hyacinth. Physiologia Plantarum, v.34, p.14-17, 1975. Disponível em: <http://onlinelibrary. wiley.com/doi/10.1111/j.1399-3054.1975.tb01847.x/full>. Acesso em: 03 jun. 2012. doi: 10.1111/j.1399-3054.1975. tb01847.x.

PILET, P.E.; BARLOW, P.W. The role of abscisic acid in root growth and gravireaction: a critical review. Plant Growth Regulation, v.6, p.217-265, 1987. Disponível em: <http://link. springer.com/article/10.1007/BF00024506>. Acesso em: 03 jun. 2012. doi: $10.1007 / \mathrm{BF} 00024506$.

RADMANN, E. B. et al. Concentrações de ácido indolbutírico e períodos de escuro, no enraizamento in vitro de amoreira-preta (Rubus sp.), cv. 'Ébano'. Revista Brasileira de Fruticultura, v.25, n.1, p.124-126, 2003. Disponível em: <http://www.scielo.br/pdf/rbf/v25n1/ a35v25n1.pdf>. Acesso em: 04 jun. 2012. doi: 10.1590/ S0100-29452003000100035.

RAVNIKAR, M. et al. Jasmonic acid stimulates shoots and bulb formation of garlic in vitro. Journal Plant Growth Regulation, v.12, p.73-77, 1993. Disponível em: <http://link.springer.com/ article/10.1007/BF00193236>. Acesso em: 10 jul. 2012. doi: 10.1007/BF00193236.

ROSSI, V. et al. Phenylurea derivatives for micropropagation of garlic meristems. Acta Horticulturae, n.394, p.263-271, 1995. Disponível em: <http://www.actahort.org/books/394/394_28.htm>. Acesso em 05 jun. 2012.

SANTOS, N.; SALEMA, R. Promotion by jasmonic acid of bulb formation in shoot cultures of Narcissus triandrus L. Plant Growth Regulation, v.30, p.133-138, 2000. Disponível em: <http://ink. springer.com/article/10.1023/A\%3A1006381127884>. Acesso em: 03 jun. 2012. doi: 10.1023/A:1006381127884.

SATO, A. Y. et al. Influência do ácido abscísico na micropropagação da cultura da mandioca (Manihot esculenta Crantz). Acta Scientiarum Maringá, v.23, n.5, p.1235-1237, 2001. Disponível em: <http://periodicos.uem.br/ojs/index.php/ActaSciAgron/article/ view/2680>. Acesso em: 05 jul. 2012.

SEABROOK, J.E.A. Narcissus (Daffodil). In: AMMIRATO, P. et al. (Eds). Handbook of Plant Cell Culture. Ornamental Species. New York: McGraw-Hill, 1990, v.5, n.24, p.577-597. 
VIEIRA, R. L. Aspectos fisiológicos e fitossanitários na micropropagação para a obtenção de alho-semente livres de vírus. Florianópolis: Centro de Ciências Agrárias, Universidade Federal de Santa Catarina, 2012, 193 p. Tese de Doutorado.

YAMAGUCHI, T.; STREET, H.E. Stimulation of the growth of excised cultured roots of soybean by abscisic acid. Annals of Botany, v.41, n.17, p.1129-1133, 1977. Disponível em: <http:/aob. oxfordjournals.org/content/41/6/1129>. Acesso em: 05 jun. 2012.

YAMAZAKI, H. et al. Involvement of abscisic acid (ABA) in bulb dormancy of Allium wakegi Araki I. Endogenous levels of ABA in relation to bulb dormancy and effects of exogenous ABA and fluridone. Plant Growth Regulation, v.29, p.189-194, 1999. Disponível em: <http://link.springer.com/article/10.1023/A\%3A1006212427997>. Acesso em: 15 jul. 2012. doi: 10.1023/A:1006212427997.

ZEL, J. et al. The effect of jasmonic acid, sucrose and darkness on garlic (Allium sativum L. cv. 'Ptujski' Jesenski) bulb formation in vitro. In vitro Cellular \& Developmental Biology Plant, v.33, p.231-235, 1997. Disponível em: <http://link.springer.com/article $/ 10.1007 \% 2 F s 11627-997-0028-4>$. Acesso em 03 jun. 2012. doi: $10.1007 / \mathrm{s} 11627-997-0028-4$. 